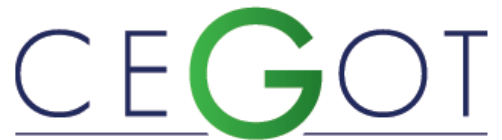

Centro de Estudos de Geografia e Ordenamento do Território
STEPHAN, ÍTALO

Universidade Federal de Viçosa, Departamento de Arquitetura e Urbanismo

36571-000, Viçosa, Brasil. Avenida P.H. Rolfs, s/n. Campus Universitário. stephan@ufv.br

RABELO, NOARA

Universidade Federal de Viçosa, Departamento de Arquitetura e

Urbanismo. Bolsista da Fundação de Amparo à Pesquisa de Minas

Gerais (FAPEMIG)

36570-900, Viçosa, Brasil

noara.rabelo@ufv.br

\title{
A segregação socioespacial nas cidades históricas de Minas Gerais: uma análise de Diamantina, MG
}

Socio-spacial segregation in the historical cities of Minas Gerais: an analysis of Diamantina, MG

Referência: Stephan, Ítalo; Rabelo, Noara (2019). A segregação socioespacial nas cidades históricas de Minas Gerais: uma análise de Diamantina, MG. Revista de Geografia e Ordenamento do Território (GOT), no 18 (Dezembro). Centro de Estudos de Geografia e Ordenamento do Território, p. 38-56, dx.doi.org/10.17127/got/2019.18.002

\section{RESUMO}

A valorização imobiliária em áreas de interesse econômico impulsionou movimentos de transformação e expansão periférica. Tal valorização pode ser relacionada com a especulação imobiliária, responsável por diversos fatores que podem levar à gentrificação e a outros problemas urbanos. O presente trabalho analisa a dualidade da valorização de diferentes espaços, que pode trazer como consequência a segregação socioespacial nas cidades, incluindo as "históricas" de Minas Gerais, às quais foi dado o enfoque do presente trabalho, inserindo como exemplo, Diamantina. Uma análise a respeito destes aspectos permitiu concluir que o espaço urbano deve ser compreendido em sua totalidade, e que a função social da propriedade não deve ser desconsiderada e superada pelo interesse imobiliário e pelo crescimento desordenado na cidade.

Palavras-chave: Segregação socioespacial; Desigualdade; Cidades históricas; DiamantinaMG

\section{ABSTRACT}

Real estate valuation in areas of economic interest boosted peripheral transformation and expansion movements. Such valuation can be related to real estate speculation, responsible for several factors that can lead to gentrification and other urban problems. The present work analyzes the duality of the valorization of different spaces, which can lead to sociospatial segregation in the cities, including the "historical" ones of Minas Gerais, to which the present work was focused, including Diamantina. An analysis of these aspects allowed us to conclude that urban space should be understood in its entirety and that the social function 
of property should not be disregarded and overcome by real estate interest and disordered growth in the city.

Key Words: Socio-spatial segregation; inequality; historical cities; Diamantina-MG

\section{Introdução}

A primeira década do século XXI foi marcada por uma intensificação da produção imobiliária no Brasil, através do aumento do volume da produção e pela valorização imobiliária. Este quadro repercutiu em mudanças estruturais na organização do setor imobiliário e na reconfiguração das cidades brasileiras (Rufino, 2016, p.218). Nesse cenário fortemente favorável à expansão do consumo da produção imobiliária, que Harvey $(2014$, p.67) colocou como "enorme bolha imobiliária", no começo da década de 2010, abriu-se a possibilidade de captar recursos do mercado financeiro. Essa estratégia do mercado imobiliário impulsionou um importante movimento de transformação e expansão das periferias das grandes metrópoles (Rufino, 2016, p.218) e nas cidades médias. No entanto, segundo Costa (2010, p.10) tais transformações não se restringem somente às grandes metrópoles e cidades médias, já que também pode ser percebido nas cidades históricas ${ }^{11}$.

A valorização imobiliária pode ser relacionada com a especulação imobiliária, responsável pelo encarecimento da moradia urbana, pela produção dos vazios urbanos com fins especulativos; pela subutilização da infraestrutura urbana e pelo encarecimento dos transportes (Gonçalves, 2010, p.1). A respeito da especulação imobiliária, Santos (1993, p.96) explicou que esta "deriva, em última análise, da conjugação de dois movimentos convergentes: a superposição de um sítio social ao sítio natural; e a disputa entre atividades ou pessoas por dada localização. A especulação se alimenta dessa dinâmica, que inclui expectativas". Assim criam-se sítios sociais, uma vez que o funcionamento da sociedade urbana transforma os lugares de forma seletiva, afeiçoando-os às suas exigências funcionais, toranndo certos pontos mais acessíveis, atrativos e valorizados. Portanto, são as atividades mais dinâmicas que se instalam nessas

\footnotetext{
${ }^{11}$ Cabe aqui tecer uma importante observação, no que se refere à adoção do termo "cidades históricas" no presente trabalho. Em que pese a amplitude do termo adotada pela Carta de Washington, que considera as cidades como históricas como um resultado da evolução das mesmas, englobando, portanto, toda e qualquer cidade (PRIMO, 1999, p.193-196), parte-se aqui de uma visão mais específica. Aqui a terminologia refere-se à cidade submetida a tombamento, e que consequentemente recebe um tratamento especial com a finalidade de conservar amplamente a memória local.
} 
áreas privilegiadas. Da mesma forma acontece quanto aos lugares de residência. As pessoas de maiores recursos buscam se alojar onde lhe pareça mais conveniente (SANTOS, 1993, p.96).

Tal valorização torna-se financeiramente inacessível para a população de menor renda, podendo levar à gentrificação, que traduz em um deslocamento de habitantes de menores níveis socioeconômicos por outros de maiores capacidades de consumo (Vergara-Constela; Casellas, 2016, p.124). Dessa forma, a população economicamente menos favorecida é deslocada para os subúrbios ou bairros desvalorizados, ou forçada a criar ou ampliar ocupações irregulares, enquanto a população de maior renda tem condições de permanecer no centro.

Segundo Rufino (2016, p.218-219), tradicionalmente a produção imobiliária do mercado, que concentra principalmente nas áreas centrais, "tendeu a reforçar a dicotomia entre centro equipado e territórios precariamente ocupados. Esses territórios precários contrastavam e valorizavam ainda mais os espaços mais bem servidos e mais equipados". Esse cenário "explicitava diferenças e levava a cidade a um rápido processo de expansão, pautado por baixa densidade e informalidade nas construções". Assim, pode-se afirmar que houve um "fortalecimento de uma visão segmentada e dual da urbanização", e não visto como uma totalidade, na qual uma produção organizada do espaço se contrapunha a outro espaço (Pereira, 2005; Rufino, 2016, p.219).

Dessa forma, o presente trabalho tem como objetivo o estudo da dualidade da valorização ${ }^{12}$ de diferentes espaços urbanos, geralmente entre o centro e periferia ${ }^{13}$, trazendo como consequência a segregação socioespacial ${ }^{14}$ nas cidades. Como já dito, isso não fica restrito às grandes metrópoles e cidades médias, afeta também em cidades históricas. Desse modo, o presente trabalho optou por analisar o problema a partir do exemplo da cidade de Diamantina, em Minas Gerais. Segundo Villaça (2012, p.43), em sua obra "Espaço intraurbano no Brasil" (p.142), a segregação é "um processo segundo o qual diferentes classes

\footnotetext{
${ }^{12}$ O termo "valorização" trata-se de conferir mais destaque e atenção de uma região da cidade perante outra. Destaque e atenção no sentido de mais investimentos, atividades, turismo, fiscalização, interesse econômico imobiliário, comercial e cultural. A respeito das Cidades Históricas, geralmente tem-se maior valorização no Centro Histórico em detrimento outra área.

${ }^{13}$ Para este trabalho, o termo "periferia" será definida como a área concentrada fora do centro da cidade, mas dentro do perímetro urbano. Para as abordagens de cidades históricas, periferia trata-se da área concentrada fora do Centro Histórico.

${ }^{14}$ Assim como Villaça $(2012$, p.46) afirma, "a forma mais tradicional do estudo da segregação urbana é aquela que aborda o centro versus periferia urbanos".
} 
ou camadas sociais tendem a se concentrar cada vez mais em diferentes regiões gerais ou conjuntos de bairros".

\section{Material e Métodos}

Foram utilizadas como metodologia de pesquisa as produções bibliográficas que problematizaram a formação da periferia, através da valorização da área central de uma cidade, expressando dessa maneira as intensas desigualdades da urbanização brasileira. Também foram utilizados mapas e fotografias; dados censitários do IBGE sobre a presença de ocupações irregulares nas cidades históricas de Minas Gerais e documentos oficiais da Prefeitura Municipal que tratam sobre loteamentos urbanos irregulares. Também foi feita análise de leis como o Estatuto da Cidade e a Constituição Federal de 1988, nas quais tratam a respeito da função social da propriedade ${ }^{15}$.

\section{A organização socioespacial e a compreensão do espaço}

Para o entendimento e análise da organização socioespacial, deve-se compreender o espaço urbano, uma vez que estão diretamente relacionados entre si. A análise da produção e organização socioespacial de uma cidade histórica, de acordo com Costa (2010, p.10), deve abranger uma visão de forma totalizada do território urbano, e não apenas focada nos limites do centro histórico. O autor aponta como problemática a análise de uma cidade histórica que não leva em consideração a organização socioespacial dessa forma, uma vez que uma "análise focada e desarticulada pode não dar conta da realidade multidimensional e em movimento da formação de novas espacialidades acarretadas pelas novas estratégias do planejamento dessas cidades do interior brasileiro". De acordo com Souza; Faria; Stephan (2015, p.143) apud Santos (1985), para compreender a organização espacial e sua evolução, é fundamental interpretar a relação entre estrutura, processo, função e forma, de modo a permitir a compreensão da totalidade social em sua espacialização. Também é

\footnotetext{
${ }^{15}$ A função social da propriedade é norma constitucional que baliza o direito de propriedade privada, fazendo com que esta atenda a um "fim específico, que, no caso, corresponde ao interesse coletivo e não ao interesse do próprio dono - embora, nada impeça que possam conviver harmonicamente". Assim, toda e qualquer questão envolvendo o direito de propriedade deve se pautar em uma interpretação que garanta a proteção dos interesses sociais (DIDIER JUNIOR, 2008, p.7-8).
} 
necessário o entendimento de como os objetos, em sua organização, estão interrelacionados. Os autores explicam que há uma necessidade da leitura do território, de modo a compreender a dinâmica e a buscar estratégias de intervenções adequadas para as cidades.

De acordo com Mendes (2011, p.477), o urbanismo deve se realizar a partir de projetos urbanos estratégicos e participativos, em busca da miscigenação funcional. Essas características induzem a evolução das cidades para um espaço policêntrico, ou seja, constituído por diversos polos de atividades, serviços e setores, concomitantemente a uma desconcentração das atividades em um único centro. Nas cidades históricas encontra-se uma área central densa de atividades econômicas, culturais e turísticas. Nas proximidades desta área central, os bairros mais recentes também podem acolher comércios e residências burguesas, predominando, portanto, camadas de rendas médias-superiores (Ascher, 1998, p.8-15).

Segundo Costa (2010, p.11), a valorização do espaço identifica a fragmentação do território urbano quando os bairros de entorno ao Centro Histórico e da periferia apresentam diversos problemas socioespaciais, "que vão desde infraestrutura urbana, como iluminação pública, falta de água, coleta de esgoto, pavimentação, equipamentos de serviços diversos, etc., até precárias moradias e elevado índice de desemprego". Pode-se conjectar que isso se deve ao fato de que as ações voltadas ao Centro Histórico resultam em uma "política de patrimônio que desvia a atenção pública e recursos de problemas mais amplos, sobretudo, fora do núcleo tombado, o que vem afetando as condições de vida da população local". Dessa forma, pode resultar em uma distinção de valorização entre as partes da cidade, produzindo um território urbano fragmentado (Costa, 2010, p.11), do ponto de vista de importância e atenção.

Ao longo do tempo, o traçado e a morfologia das cidades foram influenciados tanto pelas ações humanas quanto pela sua localização geográfica. Segundo Silveira (2015, p.16), podem ser observadas, nas áreas de expansão, "ocupações controversas do espaço", por parte da população de baixa renda, bem como das classes sociais mais abastadas. Isto se deve aos processos de especulação, e às restrições de localização dessas populações, oriundas de processos de migração e segregação, refletindo na consolidação dos padrões espaciais urbanos. $\mathrm{O}$ autor ainda insere nesse contexto, que esses espaços se colocam como 
"territórios de convivência (e conveniência) de diversas configurações e usos, limitações da legislação e complexos processos socioespaciais".

\section{A organização socioespacial e a função social da propriedade}

A partir das questões até então apontadas, que demonstram a necessidade de atenção para a organização socioespacial, na compreensão do urbanismo contemporâneo, deve se pautar pela observância de princípios que garantam a elaboração e a efetivação de políticas urbanas que enfrentem as formas de segregação, gentrificação, e perpetuação de desigualdades.

O ordenamento jurídico brasileiro teve a preocupação de incluir, em sua lei suprema, a preocupação com a questão urbanística. A Constituição da República Federativa do Brasil de 1988 traz, em seu elenco de direitos fundamentais, a previsão de que, para a garantia da propriedade (entre outros direitos), será sempre considerada sua função social ${ }^{16}$. Ainda, dedicou o seu Título VII, Capítulo II, para tratar da política urbana. Desse modo, passou a prever que a política de desenvolvimento urbano deve ser executada pelo poder público municipal, com o objetivo de "ordenar o pleno desenvolvimento das funções sociais da cidade e garantir o bem- estar de seus habitantes" ${ }^{17}$, exigindo a elaboração e aprovação da Câmara Municipal de um plano diretor, em municípios com mais de vinte mil habitantes. $\mathrm{O}$ Estatuto da Cidade (Lei 10.257/2001), traz uma série de instrumentos urbanísticos com o intuito de combater questões que dificultam o cumprimento da função social, como o combate à especulação imobiliária, para o "desenvolvimento, a estruturação e o planejamento urbanos" (Bonizzato, 2010, p. 14-15). ${ }^{18}$ Assim, a ordem normativa demonstra uma evolução no que diz respeito à criação de instrumentos aptos a combater questões como a que neste trabalho se trata: a dualidade da supervalorização dos locais tombados em centros históricos e a precarização da periferia e, como consequência, a segregação socioespacial.

\footnotetext{
${ }^{16}$ Artigo 5o, inciso XXIII da Constituição da República Federativa do Brasil (BRASIL, 1988).

${ }^{17}$ Artigo 182 da Constituição da República Federativa do Brasil (BRASIL, 1988).

${ }^{18}$ Entre os instrumentos de "ataque a práticas imobiliárias especulativas" estão: a utilização, o parcelamento e edificação compulsórios, o imposto sobre a propriedade territorial urbana (IPTU) progressivo no tempo e a desapropriação com pagamento em títulos" (BONIZZATO, 2010, p. 14-15).
} 
A desigualdade que existe na sociedade brasileira, conforme apontado por Villaça (2012, p.70-76), se manifesta na enorme segregação que se observa em nossas cidades. Tal segregação provoca um ônus para os mais pobres e vantagens para os mais ricos. Entretanto, há a consciência e o reconhecimento de que os problemas das pessoas economicamente mais pobres são diferentes dos mais ricos. "É talvez sabido que a solução dos problemas dos mais pobres depende mais do poder público e que a solução da maior parte dos problemas dos mais ricos depende mais do mercado" (Villaça, 2012, p.70-76). Quando há segregação urbana, os problemas urbanos são diferentes, conforme as regiões onde reside e atua a população mais rica. Consequentemente, as populações dessas regiões mais ricas pressionam o poder público e, faz-se necessário ressaltar que os problemas urbanos são manipulados pelos ideais dominantes. Um exemplo, de acordo com o autor, é o entendimento das questões de planejamento urbano, sobretudo, o plano diretor, que pode ser considerado como um assunto complexo, portanto, compreendido apenas por aqueles mais instruídos. Para o autor, o fato de as classes mais pobres não se interessarem ou não darem importância ao plano diretor, segundo o autor, é porque este não tem nada a lhes oferecer.

Outro exemplo que retrata tal menção é a respeito do "verde e o meio ambiente" que não estão entre os principais problemas das classes mais pobres, uma vez que representam coisas diferentes para diferentes classes sociais. Enquanto para os mais ricos "verde" significa parques, ar despoluído, silêncio e tranquilidade, para os mais pobres significa córregos imundos, insalubridade, inundações ou deslizamento de encostas. Villaça (2012, 70-76) afirma que quando há protestos reivindicando qualquer insatisfação pública, proveniente das classes economicamente mais prejudicadas, não se tem a mesma pressão política, nem o impacto causados pelas reivindicações da população mais rica, uma vez que nesta última se concentra o empresariado e o poder econômico. Por outro lado, para Stephan, outras experiências em cidades pequenas mostraram que isso não ocorre em todos as cidades: a população mais rica, ou aqueles que vivem em locais com boas condições de infraestrutura, não se interessam, e os moradores mais pobres são em maior número nas reuniões para tratar dos planos (2008, p.88).

Dessa forma, a partir das abordagens supracitadas, pode-se verificar que há a produção de um território urbano dividido quando as ações do poder público dão prioridade para a 
centralidade urbana frente à periferia. Logo, pode-se observar, de acordo com Costa (2010, p.15), o resultado de modelos segregacionistas de planejamento urbano, quando poderia surgir como um instrumento de garantia da função social, garantia da preservação do patrimônio arquitetônico e urbanístico e que mitigasse ações que estimulam a segregação territorial e a gentrificação.

Para Castriota (2004, p.55), em termos urbanísticos, deve haver a "integração entre o planejamento macro - Plano Diretor - e o planejamento para as chamadas áreas históricas', o plano especial demandado por elas". No que se refere ao Plano Diretor, segundo o autor, isso significa tratar a cidade em sua totalidade, e não apenas as áreas históricas.

Portanto, "é preciso, por um lado, atender aos interesses econômicos e, por outro, proporcionar um crescimento urbano de forma mais equilibrada e sustentável. Os interesses imobiliários e o crescimento desordenado não podem superar a função social da propriedade" (Leiva; et al, 2015, p.154).

\section{A produção de desigualdades em detrimento de diferentes níveis de valorização do espaço urbano}

No contexto de uma cidade histórica, alguns aspectos a respeito dos diferentes níveis de valorização do espaço urbano podem ser citados, para que, a partir deles, se compreenda as desigualdades presentes em diferentes espaços urbanos como o Centro e periferia. Entre estes aspectos, podem ser citados, por exemplo, a influência do tombamento, do turismo, da paisagem urbana, da paisagem cultural, do comércio, do transporte, eventos e festas.

A partir do tombamento, as áreas das cidades históricas preservadas passaram a ter nova visibilidade, e consequentemente a atrair mais turistas. O turismo traz consigo consequências positivas (a atração de renda e a geração de empregos, por exemplo), e negativas. A respeito destas consequências negativas, Coriolano, Barbosa e Sampaio (2010, p. 45-46), ressaltam o cerne da ética burguesa existente no turismo, que tem "base urbana, elitista e consumista". Para as autoras, deve-se considerar a nítida contradição entre aqueles que desfrutam do turismo daqueles que trabalham e/ou residem no mesmo 
ambiente. Os espaços turísticos tendem a ser supervalorizados, em decorrência da sua mercantilização, pois ali se encontram turistas que buscam por melhores condições de hospedagem, bons restaurantes e atividades de lazer. Assim "o turismo produz 'ilhas de prosperidade' em conflito com espaços marginais, fazendo emergir contradições, as mais diversas, especialmente de ordem espacial, social, cultural e econômica". Entre a relação turismo e urbanização, segundo Coriolano, Barbosa e Sampaio (2010, p. 45-46), "tem-se o elemento que contribui, cada vez mais fortemente, na (re)produção socioespacial de lugares turísticos, gerando dinâmicas de sociedades modernas - políticas indutoras de macromudanças socioespaciais, pelo capital imobiliário". Os processos de urbanização, consumo, competitividade e especulação são características de uma sociedade capitalista. Dessa forma, o turismo intensifica tais movimentos e processos através da indução da produção e consumo em lugares mais economicamente atrativos. Consequentemente, as áreas tombadas nas cidades históricas passaram a ser financeiramente inacessíveis às classes mais baixas da população, produzindo a desigualdade entre aqueles que podem desfrutar dos preços praticados nas áreas turísticas, e aqueles que se veem forçados a se deslocar para áreas periféricas.

Pode-se fazer uma analogia com o tipo de cidade que Vainer $(2000, p .78)$ insere em seu contexto de Planejamento Estratégico Urbano, onde "a cidade é uma mercadoria a ser vendida". O autor coloca que o que se vende quando se põe à venda uma cidade, dependerá de quem se tem em vista como comprador, de acordo com suas características. No caso das cidades históricas, busca-se atividades culturais e de lazer que, consequentemente atraem visitantes e usuários "compradores" destes produtos. Vale ressaltar que, segundo Vainer (2000, p.82), a transformação da cidade em mercadoria repercute sobre a sociedade economicamente menos favorecida, uma vez que a "mercadoria-cidade tem um público consumidor muito específico e qualificado". Este público concentra os grupos de elite, detentores de capital, que são potenciais compradores na cidade, exemplificado pelo autor como visitantes e usuários solváveis (VAINER, 2000, p.82). A partir desta discussão questiona-se quanto àqueles indivíduos e grupos que não têm solvabilidade para adquirir esse produto de possível acesso à elite. Portanto, pode-se perceber a segregação social quanto às atividades nas cidades históricas nas quais concentram no Centro Histórico. 
De acordo com Vergara-Constela e Casellas (2016, p.127), através do interesse nas cidades de institutos/organizações patrimoniais e culturais, como o IPHAN e a UNESCO, as cidades têm revalorizado o significado de patrimônio urbano. O resultado, segundo os autores, é a identificação de um potencial econômico do patrimônio arquitetônico vinculado à sua exploração turística. Vale ser mencionado o reconhecimento do valor histórico de um bem, ou de um conjunto, de determinada área da cidade, por institutos/organizações patrimoniais e culturais, transformando-o em patrimônio oficial público. Tal ação traz consigo um custo oneroso de manutenção dos imóveis e os proprietários, muitas vezes, ficam impossibilitados de arcar com tal despesa. Dessa forma, após serem vendidos, o espaço passa a ter outras funções. Estas consequências fazem com que o morador destas áreas, que ainda possuía condições de resistir, não tivesse mais possibilidade de continuar a morar no local. O morador vende o imóvel que vai ter outro uso, caracterizando, portanto, o centro histórico como um local primordialmente turístico, comercial e de serviços. Pode ser mencionado, por exemplo, a transformação dos antigos imóveis em hotéis, centros culturais, restaurantes, lojas de lembranças (Leite, 2013, p.167; Vergara-Constela e Casellas, 2016, p.127). Portanto, pode-se conjecturar que tais fenômenos podem intensificar o processo da gentrificação e da segregação territorial.

Em cidades históricas que passam por estes processos, segundo Leite (2013, p.184), surgem a segregação socioespacial e ocupações irregulares. Leiva; et al (2015, p.154) destacam a que ocupação irregular tem aumentado em razão da ausência do devido controle urbanístico e regularização. Vale destacar dois aspectos. O primeiro, há, por um lado, um Centro Histórico concentrado de atenção por parte do Poder Público, equipado de edificações comerciais, hoteleiras e restaurantes, que recebe investimentos e atividades econômicas, ocupado por visitantes e usuários com condições financeiras para usufruir de tal. Por outro lado, há uma periferia negligenciada e descuidada, com poucas atividades comerciais, e ocupada, em grande parte, de forma irregular por aqueles que não têm condição de permanecer residentes no Centro. Dessa forma, a partir destes diferentes níveis de valorização do espaço urbano somado à produção de desigualdades sociais, tem-se como consequência para o cenário urbano o comprometimento da paisagem da cidade além do impacto, principalmente na sociedade menos favorecida economicamente, em razão da desordenada apropriação de ocupações irregulares. 
De acordo com o Instituto Brasileiro de Geografia e Estatística - IBGE no censo de 2017, em pesquisa do perfil dos Municípios de Serro, Diamantina, Tiradentes, São João del Rei, Ouro Preto e Mariana, a respeito das habitações, fez-se um levantamento da presença/ ausência de favelas, cortiços e loteamento irregulares, como pode ser observado no quadro a seguir:

Quadro 1 - Presença de Favelas, Cortiços e Loteamentos Irregulares

\begin{tabular}{c|c|c|c|c|c|c}
\hline & Serro & Diamantina & Tiradentes & $\begin{array}{c}\text { São João } \\
\text { del Rei }\end{array}$ & Ouro Preto & Mariana \\
\hline $\begin{array}{c}\text { Favelas, } \\
\text { mocambos, } \\
\text { palafitas ou } \\
\text { assemelhados }\end{array}$ & Não & Sim & Não & Não & Não & Não \\
\hline $\begin{array}{c}\text { Cortiços, casas } \\
\text { de cômodos } \\
\text { ou cabeças- } \\
\text { de-porco }\end{array}$ & Sim & Sim & Não & Não & Não & Não \\
\hline $\begin{array}{c}\text { Loteamento } \\
\text { irregulares } \\
\text { e/ou }\end{array}$ & Sim & Não* & Sim & Sim & Sim & Sim \\
clandestinos & Não & Não & Não & Não & Não & Não \\
$\begin{array}{c}\text { terrenoções de } \\
\text { prédios por } \\
\text { movimentos } \\
\text { de moradia }\end{array}$ & Ne & & & \\
\hline
\end{tabular}

* De acordo com documentos oficiais atualizados da Prefeitura Municipal de Diamantina (2018), há alguns loteamentos irregulares no município de Diamantina, considerando a sede e os distritos. Ver "Loteamentos Urbanos: Fiscalização entre 07 e 08 de novembro de 2017". Segue a nota do documento: "Tendo em vista investigação por parte do Ministério Público quanto a irregularidades de parcelamento de solo (loteamentos urbanos e rurais) e tendo em vista que muitos dos loteamentos se encontravam com licenças ambientais municipais vencidas a mais de 02 anos e inclusive sem julgamento de recursos e com multas a serem cobradas arquivadas. Foi necessário um levantamento da situação dos loteamentos urbanos para adequar os mesmos a legislação em vigência e realidade local e garantir os direitos dos cidadãos vítimas das compras destes imóveis irregulares e resguardar também a Administração (...)".

Fonte: Elaborado pelos autores a partir dos dados do IBGE (2017). 
Pode-se perceber alguma das mazelas presentes em Diamantina como a presença de favelas, cortiços e loteamentos irregulares e clandestinos. O IBGE não aponta loteamentos irregulares no Município, no entanto, de acordo com documentos oficiais atualizados da Prefeitura Municipal de Diamantina (2018), há alguns loteamentos irregulares, considerando a sede e os distritos (Quadro 1). Para o presente trabalho, interessa apenas o distrito sede. A Prefeitura informou que não possui dados numéricos a respeito da questão, no entanto, aponta alguns nomes de loteamentos irregulares do distrito sede, que são: Condomínio Bicas, Loteamento Quinto do Ouro, Condomínio Taj Mahal, Condomínio Villa Pietá, loteamento Vale dos Diamantes, Bairro Campo Belo e, os clandestinos são o Bairro Prata e o loteamento São Luiz (Prefeitura Municipal De Diamantina, 2018). Dessa forma, percebe-se que em Diamantina a irregularidade não se concentra apenas em bairros de baixo padrão.

A título exemplificativo pode-se citar a histórica Diamantina, município de Minas Gerais, que começou a se desenvolver no século XVIII, devido à exploração mineral. Inicialmente conhecida como Arraial do Tijuco, Diamantina teve o seu crescimento despertado pela descoberta de diamantes na região, e recebeu, em 1831, e por esta razão, sua denominação atual. Ainda hoje é possível visitar, no centro histórico de Diamantina, edificações do período colonial, incluindo as igrejas construídas nos séculos XVIII e XIX, e na primeira metade do século XX (Figura 1). A cidade ainda preserva tradições ligadas à religião, ao folclore e à música. Por estas razões, o tombamento da cidade pelo Instituto do Patrimônio Histórico e Artístico Nacional (IPHAN) ocorreu em 1938, juntamente com Serro, Ouro Preto, Mariana, São João del Rei e Tiradentes, e, mais tarde, em 1999, foi considerada pela Organização das Nações Unidas para a Educação, a Ciência e a Cultura (UNESCO) ${ }^{19}$, como Patrimônio Cultural da Humanidade (Albuquerque, 2012, p.207).

\footnotetext{
${ }^{19}$ Acrônimo de United Nations Educational, Scientific and Cultural Organization.
} 

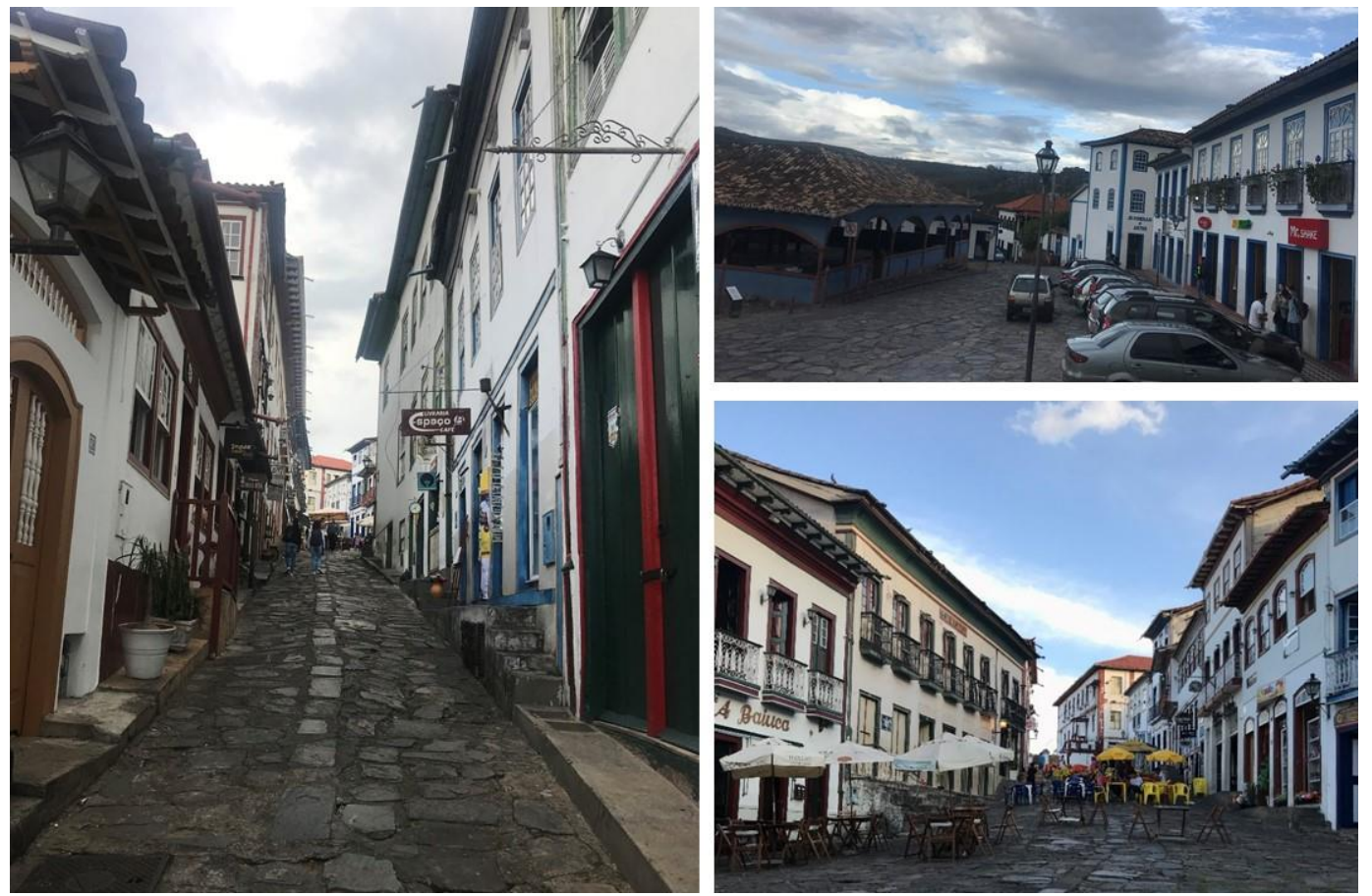

Fig. 1 - Sequência de edificações do Centro Histórico de Diamantina, MG

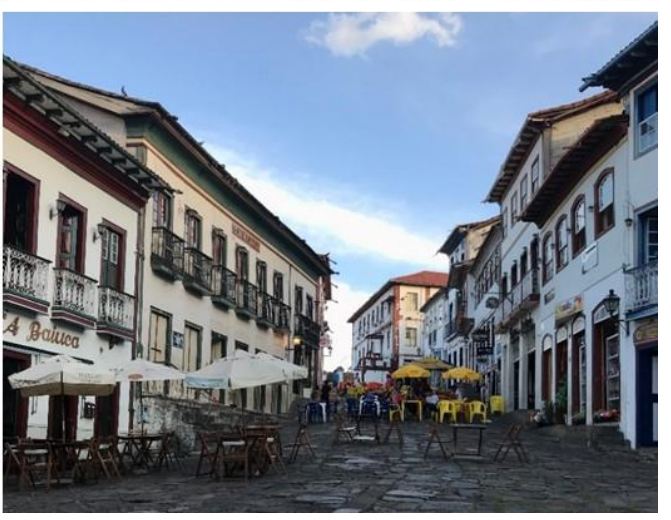

Fonte: Elaboração própria (2018).

Pode-se perceber a presença de atividade comercial no Centro Histórico de Diamantina. A foto à esquerda mostra o famoso Beco da Tecla, onde há vários bares e restaurantes. Este beco localiza-se entre a Praça, na qual está o Mercado Velho (foto superior direita), e a Rua da Quitanda (foto inferior direita). A Rua da Quitanda, exclusiva para pedestres, é um dos locais mais frequentados do Centro Histórico de Diamantina, por concentrar os mais tradicionais bares e comércios da cidade. Além disso, trata-se do local onde ocorre a tradicional Vesperata e onde situa-se a Casa Muxarabiê, atual Biblioteca Pública, importantes atrativos turísticos.

Diamantina passou por um processo de valorização do Centro Histórico, trazendo consigo movimentos de transformação do espaço e da paisagem urbana, como um alto grau de ocupação da área central e a expansão de novas áreas. Isto corrobora a afirmação de Silveira, Silva e Silva (2015, p.29), quando dizem que estas têm sido ocupadas por novas edificações, condomínios e loteamentos de média e alta renda, através de práticas estabelecidas a partir do interesse dos diversos atores. Um destes atores que influenciou e influencia na expansão de novas áreas da cidade foi a implantação das universidades UFVJM e UEMG. De acordo com Carvalho e Mendes (2014, p.232), a presença de estudantes, docentes, funcionários e novos investidores aumentou a demanda de moradias, que além de ocupar o Centro Histórico, aumentou o crescimento urbano periférico. Novos loteamentos e bairros foram criados ao longo das estradas que são rotas para a UFVJM, como o loteamento Quinto do Ouro, em 2008, o Jardim Imperial, em 2010 e o condomínio 
Taj Mahal, em 2011. Outros atores também influenciaram a expansão de novas áreas ao longo do tempo, de modo que modificações da mancha urbana, como novas edificações, novos loteamentos e bairros, podem ser percebidas pela Figura 2.

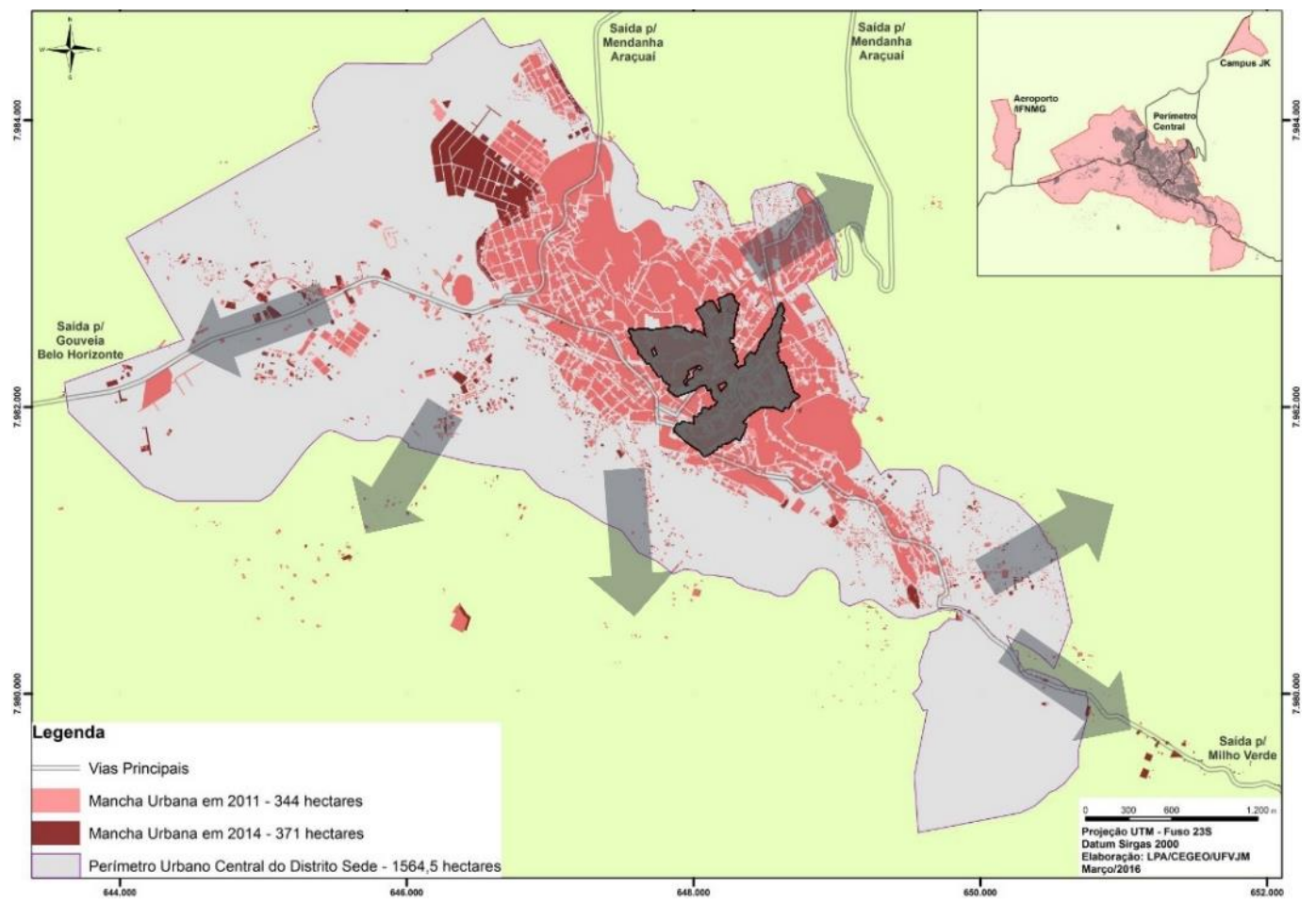

Fig. 2 - Modificações da mancha urbana de Diamantina (2011-2014)

Fonte: Elaboração própria a partir de LPA (2016).

As setas indicam a direção de crescimento da mancha urbana. A sede da cidade em 2011 apresentava uma mancha urbana de 344 hectares, que ocupava $21,6 \%$ do perímetro urbano. Já em 2014 a mancha urbana apresentou crescimento de 27 hectares, chegando de 371 hectares. Em número de edificações, em 2011 foram quantificados 11.643. Dentre estas, 310 se encontravam fora do perímetro urbano. Em 2014 foram identificadas 2.686 novas edificações, totalizando 14.329 edificações, das quais 500 estavam fora do perímetro urbano (FIDELIS; UMBELINO, 2016, p.15).

No eixo de expansão a Oeste da cidade, pode ser identificada a presença de investimentos imobiliários no setor de habitação de alto valor. De acordo com a Imobiliária Solar (2018), Sentinela Imóveis (2019) e Camaleão Corretora Imobiliária (2019), o valor do lote nos bairros Taj Mahal e Bicas, por exemplo, situados nesse eixo, é similar a alguns bairros situados em uma região mais próxima ao Centro, como o Bairro Jardim Imperial e Bairro Fátima, ambos de média-alta renda. Os valores de compra dos lotes no Taj Mahal são em torno de $\mathrm{R} \$ 300,00$ o metro quadrado, com lotes de 1.000 metros quadrados; no 
Condomínio Bicas, um lote de 400m² é anunciado em 2019 no valor de $\mathrm{R} \$$ 100.000,00; no Jardim Imperial o valor é cerca de $\mathrm{R} \$ 250,00$ o metro quadrado, com área de 300 a 400 metros quadrados. Em relação ao Centro, os valores variam entre $R \$ 1.000,00$ e $R \$ 3.000,00$ o metro quadrado, já com a edificação de área entre 90 e 400 metros quadrados. 0 valor do aluguel nestes bairros também é similar. Nos bairros Fátima e Jardim Imperial, o aluguel de um apartamento de 2 quartos é em torno de $R \$ 1.000,00$ bem como o valor de aluguel de uma casa de 2 quartos no Centro. Os bairros citados neste parágrafo são os de mais alto padrão em Diamantina.

A expansão de novas áreas em Diamantina, no entanto, também apresenta certa precarização, como irregularidades perante a legislação urbana, exemplificada pela ocupação desordenada da Serra dos Cristais $^{2021}$, onde predomina habitações precárias ${ }^{22}$ e sem infraestrutura adequada (Figura 3, Figura 4, Figura 5). Varajão (2015) afirma que

"ainda que a formação urbana do Arraial do Tijuco tenha sido peculiar e, portanto, justifique o reconhecimento que Diamantina atualmente detém pelo seu patrimônio cultural, a cidade lamentavelmente reproduziu diversas mazelas comuns a muitas outras aglomerações de países em desenvolvimento. A concentração de investimentos nas áreas centrais e a expansão periférica espontânea acirraram o dualismo existente entre a cidade formalmente planejada e a irregular. Reverter a situação aqui esboçada ou, ao menos, interromper o agravamento da mesma, é um grande desafio para o planejamento urbano" (Varajão, 2015, p.136-137).

Observa-se, em Diamantina, que sua periferia apresenta, em grande parte, uma população de baixa renda e espaços desvalorizados. Isto se deve principalmente aos processos de mercantilização do patrimônio e do turismo ocorridos no Centro Histórico, que levaram a uma valorização do mesmo, ocasionando fenômenos urbanos como a segregação socioespacial.

\footnotetext{
${ }^{20}$ A Serra dos Cristais, também conhecida como Serra do Rio Grande, foi tombada pelo Instituto Estadual do Patrimônio Histórico e Artístico de Minas Gerais (IEPHA) em 2010 (IEPHA, 2016). Portanto, pode-se perceber que também é uma área irregular do ponto de vista patrimonial.

${ }^{21} \mathrm{Em}$ meados de 1970, ocupações desordenadas de habitações se tornaram visíveis (CARVALHO; MENDES, 2014, p.231). Residências de pequenas dimensões e de construção precária passaram a ocupar os maciços de pedras utilizando-as como os próprios alicerces das edificações. O bairro do Rio Grande, inicialmente povoado apenas na base da Serra, próximo às margens do Rio, se adensou rapidamente e, a partir da década de 1980, construções foram instaladas além dos limites das margens no sentido da parede da Serra.

${ }^{22}$ Aqui entendidas por apresentar um aspecto construtivo precário e, em algumas regiões, como o Bairro Rio Grande, sem infraestrutura adequada, como saneamento básico.
} 
A migração da população de uma área central e valorizada para uma área periférica e precarizada, atinge predominantemente a parcela da população de baixa renda. Dessa forma, esta população acaba residindo em favelas, áreas desvalorizadas, e/ou áreas periféricas, e acaba até mesmo forçada a criar ou ampliar ocupações irregulares. Esses exemplos retratam os fenômenos de periferização, bem como gentrificação. Trata-se de uma disputa por localizações no espaço urbano e uma luta de classes, na qual se envolvem os sistemas econômicos, políticos e ideológicos pela classe dominante.

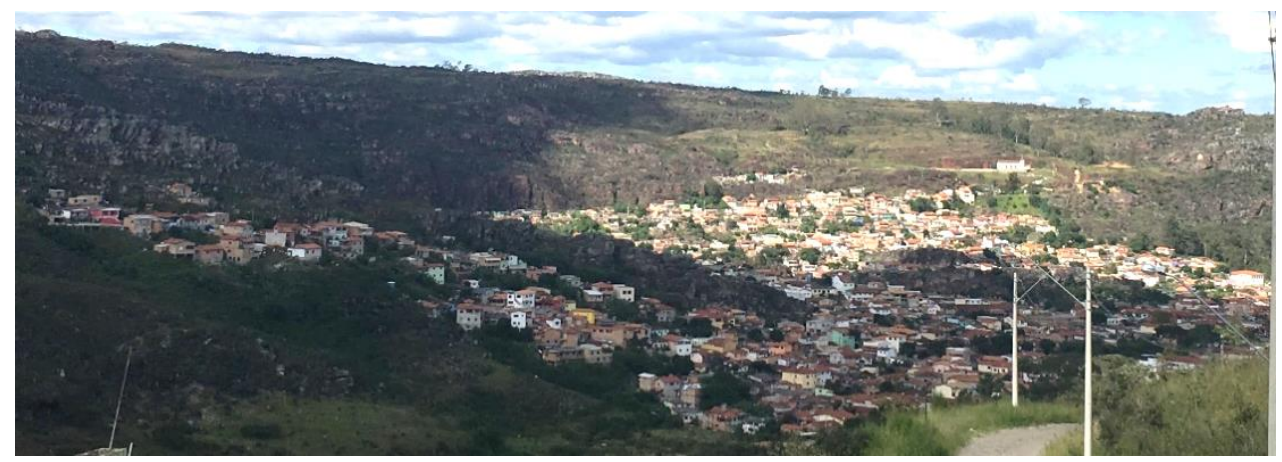

Fig. 3 - Integração da ocupação da Serra dos Cristas ao entorno do conjunto tombado como Patrimônio da Humanidade pela UNESCO.

Fonte: Elaboração própria (2018).

Ocupação da Serra dos Cristais localizada no Bairro Rio Grande indicado na foto. Vista do Bairro Pedra Grande.

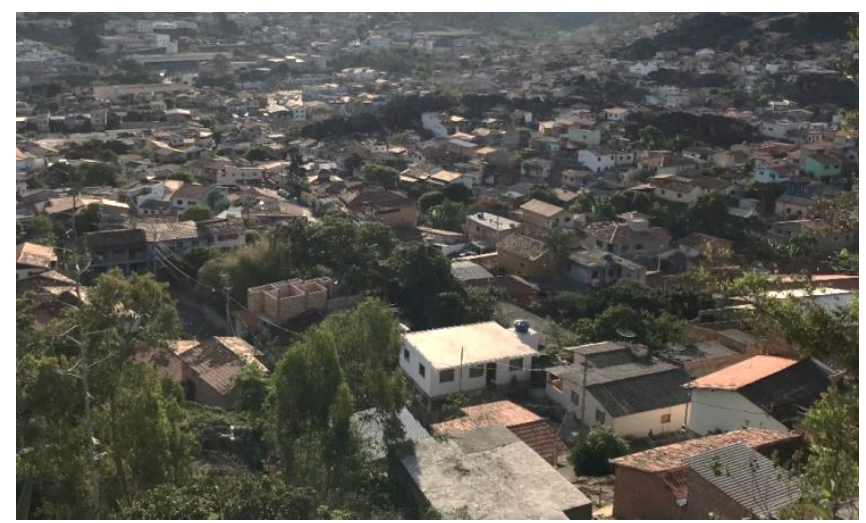

Fig. 4 - Ocupação da Serra dos Cristais pelo Bairro Rio Grande

Fonte: Elaboração própria (2018).

Foto tirada do topo da Serra dos Cristais com vista do Bairro Rio Grande. Observa-se a conexão entre a ocupação da Serra, pelo bairro Rio Grande, e o Centro Histórico. Pode-se perceber que tal ocupação, acontece de forma desordenada com edificações de aspecto construtivo precário. 

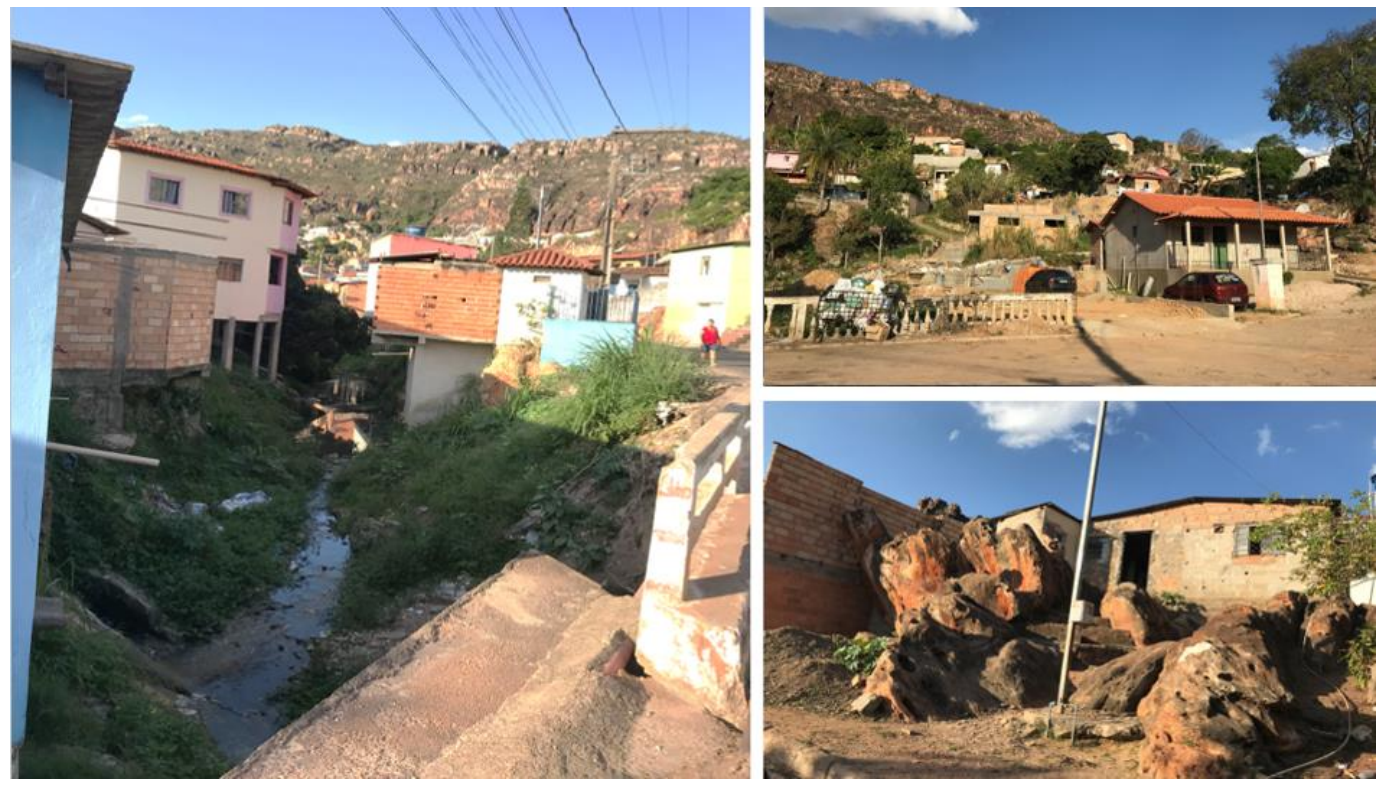

Fig. 5 - Sequência de edificações do Bairro Rio Grande, na região da Serra dos Cristais, situado na periferia de Diamantina, MG

Fonte: Elaboração própria (2018).

Edificações de aspecto precário construídas sobre os maciços rochosos da Serra dos Cristais, comprometendo a paisagem local e poluindo cursos d'água.

\section{Considerações Finais}

Diamantina possui diferentes níveis de valorização entre o Centro e a periferia. Enquanto se tem o Centro Histórico equipado e com a concentração de investimentos e atividades econômicas, sobretudo o turismo, tem-se a periferia com descaso ou desatenção enquanto espaço urbano. Através da concentração de investimentos e atividades no Centro, tem-se como consequência a valorização imobiliária que impulsiona movimentos de transformação do espaço e expansão periférica de forma desorganizada ou não planejada. Dessa forma, a valorização de diferentes espaços em diferentes níveis pode trazer como consequência a gentrificação e a segregação socioespacial nas cidades históricas.

Portanto, a compreensão das formas de produção do espaço urbano é decisiva para o entendimento das desigualdades urbanas. O espaço urbano deve ser compreendido em sua totalidade, e não em um espaço fragmentado como centro e periferia, área histórica e áreas marginais.

A concentração de atenção e investimentos nas áreas centrais e a expansão periférica espontânea contribuem para o dualismo existente entre a cidade formalmente planejada e 
a cidade irregular. Reverter a atual situação ou, ao menos, reduzir o agravamento da mesma, é um grande desafio para o planejamento urbano.

Por um lado, tem-se o interesse econômico imobiliário e, por outro, a necessidade da redução da desigualdade socioespacial. Entretanto, o cumprimento da função social da propriedade deve ser considerado e não pode ser superado pelo interesse imobiliário e pelo crescimento desordenado. É preciso utilizar os instrumentos de ordenação do espaço, de modo a impedir a segregação socioespacial, a gentrificação, fenômenos que geram impactos sobre a paisagem cultural e sobre a sociedade.

\section{Referências}

ALBUQUERQUE, Fernanda de Alencar Machado. Diamantina: Patrimônio Cultural da Humanidade. Disegnarecon, v.5, n.10, p. 207-210, nov. 2012.

ASCHER, François. Metapolis: acerca do futuro da cidade. Oeiras: Celta Editora, 1998.

BONIZZATO, Luigi. A Constituição Urbanística e elementos para a elaboração de uma teoria do Direito Constitucional Urbanístico. Rio de Janeiro: Lumen Juris, 2010.

BRASIL. [Constituição (1988)]. Constituição da República Federativa do Brasil de 1988. Brasília, DF: Presidência da República, 1988.

CAMALEÃO CORRETORA IMOBILÁRIA. Imóveis: Compra e venda. Disponível em: https://camaleaoimoveis.com.br/imovel/lote-urbano-plano-situado-na-entrada-do-cond-bicas-excelentelocalizacao/. Acesso em: 15 set. 2019.

CARVALHO, Elizabeth Sales de; MENDES, Evandro Rocha. Diamantina: Serra dos Cristais. In: INSTITUTO ESTADUAL DO PATRIMÔNIO HISTÓRICO E ARTÍSTICO DE MINAS GERAIS - IEPHA/MG (ed). Guia de Bens Tombados IEPHA/MG. 2. ed. Belo Horizonte: IEPHA/MG, 2014, p.231-234.

CASTRIOTA, Leonardo Barci. Plano diretor e reabilitação de áreas centrais e sítios históricos. In: BRASIL. Plano diretor participativo: guia para elaboração pelos municípios e cidadãos. Brasília: Ministério das Cidades, 2004. p.53-58.

CORIOLANO, Luzia Neide Menezes Teixeira; BARBOSA, Luciana Maciel; SAMPAIO, Camila Freire. Veraneio, turismo e especulação imobiliária no Porto das Dunas - Litoral Cearense. Aportes y Transferencias, v. 14, n. 1, p.43-58, 2010.

COSTA, Everaldo Batista da. Da valorização do espaço à fragmentação articulada do território urbano: a cidade histórica para além dos limites do tombamento. GEOUSP, São Paulo, n. 28, p.9-32, 2010.

DIDIER JUNIOR, Fredie. A função social da propriedade e a tutela processual da posse. 2008. Disponível em: http://www.direito.mppr.mp.br/arquivos/File/Politica_Agraria/3diderjrfuncao

social.pdf. Acesso em: 02 fev. 2019.

FIDELIS, Vinicius Paulino; UMBELINO, Glauco. Análise da expansão urbana em Diamantina entre 2011 e 2014. In: SEMINÁRIO SOBRE A ECONOMIA MINEIRA, 17, Anais do XVII Seminário sobre a Economia Mineira. Diamantina: CEDEPLAR, v. 2, 2016. p.1-10.

GONÇALVES, Juliano Costa. A especulação imobiliária na formação de loteamentos urbanos: um estudo de caso. Rio de Janeiro: E-papers, 2010.

HARVEY, David. Cidades rebeldes: do direito à cidade à revolução urbana. São Paulo: Martins, 2014. 
IBGE - INSTITUTO BRASILEIRO DE GEOGRAFIA E ESTATÍSTICA. MUNIC - Plano dos Municípios Brasileiros. 2017. Disponível em: <https://cidades.ibge.gov.br/>. Acesso em: 25 jul. 2018.

IEPHA - Instituto Estadual do Patrimônio Histórico e Artístico de Minas Gerais. Serra dos Cristais. 2016. Disponível em: http://www.iepha.mg.gov.br/index.php/programas-e-acoes/patrimonio-culturalprotegido/bens-tombados/details/1/100/bens-tombados-serra-dos-cristais. Acesso em: 06 maio 2019

IMOBILIÁRIA SOLAR. Pesquisa de lotes para venda. 2018. Disponível em: https://imobiliariasolar.com/\#. Acesso em: 10 jul. 2019.

LEITE, Rogerio Proença. Consuming heritage. Vibrant, Brasília, v. 10, n. 1, p.165-189, 2013.

LEIVA, Guilherme. et al. Análise da área de expansão urbana do município de Diamantina. In: SATHLER, Douglas; AMORIM FILHO, Oswaldo Bueno; VARAJÃO, Guilherme Fortes Drummond Chicarino (org.). Cidades médias: Bases teóricas e estudos aplicados a Diamantina, MG. Belo Horizonte: Fino Traço. 2015. p. 135-154.

LPA - Laboratório de População e Ambiente. Geotecnologias aplicadas ao Cadastro Multifinalitário de Diamantina. Relatório de pesquisa (circulação restrita). Diamantina: LPA/CEGEO/UFVJM, 2016.

MENDES, Luís. Cidade pós-moderna, gentrificação e a produção social do espaço fragmentado. Cadernos Metrópole, São Paulo, v. 13, n. 26, p. 473-495, jul./dez. 2011.

PEREIRA, Paulo Cesar Xavier. Dinâmica imobiliária e metropolização: a nova lógica do crescimento urbano em São Paulo. Scripta Nova, Barcelona, v. 10, n. 194, 2005.

PREFEITURA MUNICIPAL DE DIAMANTINA. Loteamentos urbanos: fiscalização entre 07 e 08 de novembro de 2017. 2018. Slides.

PRIMO, Judite. Museologia e patrimônio: documentos fundamentais - organização e apresentação. Cadernos de Sociomuseologia, Lisboa, n. 15, p.193-196, 1999.

RUFINO, Maria Beatriz Cruz. Transformação da periferia e novas formas de desigualdades nas metrópoles brasileiras: um olhar sobre as mudanças na produção habitacional. Cadernos Metrópole, v. 18, n. 35, p.217236, 2016.

SANTOS, Milton. A Urbanização brasileira. São Paulo: Hucitec, 1993.

SENTINELA IMÓVEIS. Imóveis em Diamantina. Galax Imóveis. 2019. Disponível em: http://www.galaximoveis.com.br/buscar-imoveis/todos-tipos/mg/diamantina/todos-bairros/0/1/53/0/40/ mais-favoritados/0/0/0/-/0-0. Acesso em: 17 jul. 2019.

SOUZA, Kelly Diniz de; FARIA, Teresa Cristina de Almeida, STEPHAN, Ítalo Itamar Caixeiro. Processo de Formação Socioespacial de Pequenas Cidades: o caso de Serro. Oculum Ensaios, Campinas v. 12, n. 1, p.141155, jan./ fev. 2015.

VAINER, Carlos Bernardo. Pátria, empresa e mercadoria: Notas sobre a estratégia discursiva do Planejamento Estratégico Urbano. In: ARANTES, Otília; VAINER, Carlos Bernardo; MARICATO, Ermínia. A cidade do pensamento único: desmanchando consensos. Petrópolis, RJ. Vozes. 2000.

VARAJÃO, Guilherme Fortes Drummond Chicarino. Por uma geografia de Diamantina-MG. 2015. Tese (Doutorado em Geografia), Universidade Federal de Minas Gerais, Belo Horizonte, 2015.

VERGARA-CONSTELA, Carlos; CASELLAS, Antonia. Políticas estatales y transformación urbana: ¿hacia un proceso de gentrificación en Valparaíso, Chile?. EURE, Santiago, v. 42, n. 126, 2016. p.123-144.

VILLAÇA, Flávio. Reflexões sobre as cidades brasileiras. São Paulo: Studio Nobel, 2012. 